MATEC Web of Conferences 9, 02011 (2013)

DOI: $10.1051 /$ matecconf/20130902011

(C) Owned by the authors, published by EDP Sciences, 2013

\title{
Performance of different fire retardant products applied on Norway spruce tested in a Cone calorimeter
}

\author{
Josef Kögl, Paul Hartmann and Wilfried Beikircher \\ Department of Engineering Science, Timber Engineering Unit, University of Innsbruck, \\ Innsbruck, Austria
}

\begin{abstract}
On the European market there are several fire retardant products available, which reach class B in the European classification system. The producers promise their fire retardants are effective in reducing different reaction to fire parameters of wood such as the time to ignition, the mass loss rate, the heat release rate, the total heat release, the charring rate and the flame spread. This paper discusses the performance of fire retardant products as pressure impregnated wood, non-intumescence surface coatings and intumescence coatings on Norway spruce (Picea abies). The investigations are performed by using a cone calorimeter test according to ISO 5660. The thermal exposures of the investigations are $50 \mathrm{~kW} / \mathrm{m}^{2}$ and the standard IS0 834 test curve. As result information about the heat release rate, the mass loss rate and the total heat release for duration of 900 seconds will be presented in this paper.
\end{abstract}

\section{INTRODUCTION}

Due to its versatile practicability as building material wood is been used in construction both structurally and as a decorative material. The advantages for using wood as building material are the minimal environmental pollution and a range of excellent technical properties. The disadvantage for using wood is its natural combustibility if exposed to severe fire conditions.

However, wood products can be used safely by improving their fire performance which includes chemical, biochemical and physical modification. At present, the level of knowledge of wood products with improved fire performance is not high enough for their extensive utilization. The main problems are not clear defined technical requirements in building standards and not existing investigation regarding the long term behaviour under different environmental conditions [1]. Even though some wood products with improved fire performance exhibit excellent fire properties and reach class B in the European standard EN 13501-1 [3]. Another problem is the selection of an unsuitable product for a certain application [2].

This paper describes the performance of fire retardant products as pressure impregnated wood, nonintumescent surface coatings and intumescent coatings by using the cone calorimeter test according to ISO 5660 [4]. The tested fire retardant products are transparent or colorless to preserve the natural character of wood for applications such as claddings, ceilings and structures.

\section{MATERIALS}

Five test series were investigated. Two intumescent coatings, a fire retardant surface coating, a pressure impregnated treatment and the reference test series. The applied quantities of fire retardant treatment can be seen in Table 1 .

This is an Open Access article distributed under the terms of the Creative Commons Attribution License 2.0, which permits unrestricted use, distribution, and reproduction in any medium, provided the original work is properly cited. 
Table 1. Fire retardant treated Norway spruce - test series.

\begin{tabular}{|l|c|l|l|l|c|}
\hline & & & & Sample \\
Test series & Replications & Fire retardant product & colour & $\begin{array}{l}\text { applied quantity } \\
{\left[\mathbf{g} / \mathbf{m}^{\mathbf{2}}\right]}\end{array}$ & $\begin{array}{l}\text { thickness } \\
{[\mathbf{m m}]}\end{array}$ \\
\hline A1 & 3 & intumescent coating & transparent & 350 & 30 \\
\hline A2 & 3 & intumescent coating & transparent & 350 & 30 \\
\hline C1 & 3 & fire retardant solution & transparent & 300 & 30 \\
\hline C2 & 3 & fire retardant treatment & transparent & $91,2 \mathrm{~kg} / \mathrm{m}^{3}$ & 20 \\
\hline REF & 3 & Natural Wood - reference & - & \multicolumn{2}{|c|}{-} \\
\hline
\end{tabular}

For each test series three replications were performed. Each test series were cut out of the same three boards of deflect free Norway spruce. The underlying wood was selected in that way to have twin samples and the influence on the natural wood properties is minimized (see Fig. 2).

After the coating resp. the impregnation the samples were conditioned at laboratory conditions at $65 \% \mathrm{RH}$ and $20^{\circ} \mathrm{C}$ for at least four weeks prior to testing to meet equilibrium moisture content (EMC).

The test dimension of the Norway spruce sample is $100 \times 100 \mathrm{~mm}$ with a thickness of $30 \mathrm{~mm}$ for series A1, A2, C1 and REF. Series C1 is tested with a thickness of $20 \mathrm{~mm}$ (see Table 1).

\section{METHODS}

Test Facility: To obtain a closed system, a mass loss cone is placed in a conditioning cabinet. Two pipes are fixed on the conditioning cabinet - one pipe for the input air on the bottom and one pipe for the exhaust gas on the top of the conditioning cabinet. In each pipe the gas flow velocity and the gas temperature is measured. In the exhaust pipe, on the top of the conditioning cabinet, the exhaust gas components are measured with a flue analyser. The measured values of the flue analyser are the content of oxygen, carbon monoxide, carbon dioxide and carbon hydrates. Furthermore, the mass of the sample and temperatures in different layers of the sample is measured. All the measured values are continuous recorded each second. With this arrangement it is possible to perform investigations according to ISO 5660 [4].

Fire tests: Before testing the specimen were wrapped into aluminium foil to approximate real scale moisture transport behaviour. Then the specimen is placed in a sample holder, which is positioned on a balance. The top of the specimen is located $25 \mathrm{~mm}$ under the bottom of the conical heater. The area of the sample, exposed to the radiation, is $0.009 \mathrm{~m}^{2}$. A split shutter mechanism protects the area of the sample before the test. The shutter is manually opened with a mechanical lever. The start of the test, $\mathrm{t}=0$ is defined by the moment the shutter is opened exposing the specimen to the radiant heat flux.

The tests were made with two different radiant heat fluxes. A continuous flux of $50 \mathrm{~kW} / \mathrm{m}^{2}$ 20 minutes test duration and a stepwise increased flux approximating the standard temperature time curve (according to ISO 834 [5] see Fig. 1) for 30 minutes test duration. The Standard ISO 834 curve increases the heat flux from low levels $\left(<25 \mathrm{~kW} / \mathrm{m}^{2}\right)$ at test start to high levels $\left(<35 \mathrm{~kW} / \mathrm{m}^{2}\right)$ after about 9 minutes, which describes a natural fire.

The test results, presented in this paper, are the mass loss rate (MLR), the heat release rate (HRR), the total heat released (THR) and the burning rate for test duration of 900 seconds.

\section{RESULTS AND DISCUSSION}

First the mass loss rate (MLR) and the total mass loss (TML) is presented and discussed. The TML 900 is the integral over the MLR from $t=0$ to $t=900 \mathrm{~s}$. The mass loss rate at $t_{0}=0$ is not fully correctly given in Fig. 3 and Fig. 4 due to the calculation method used. 

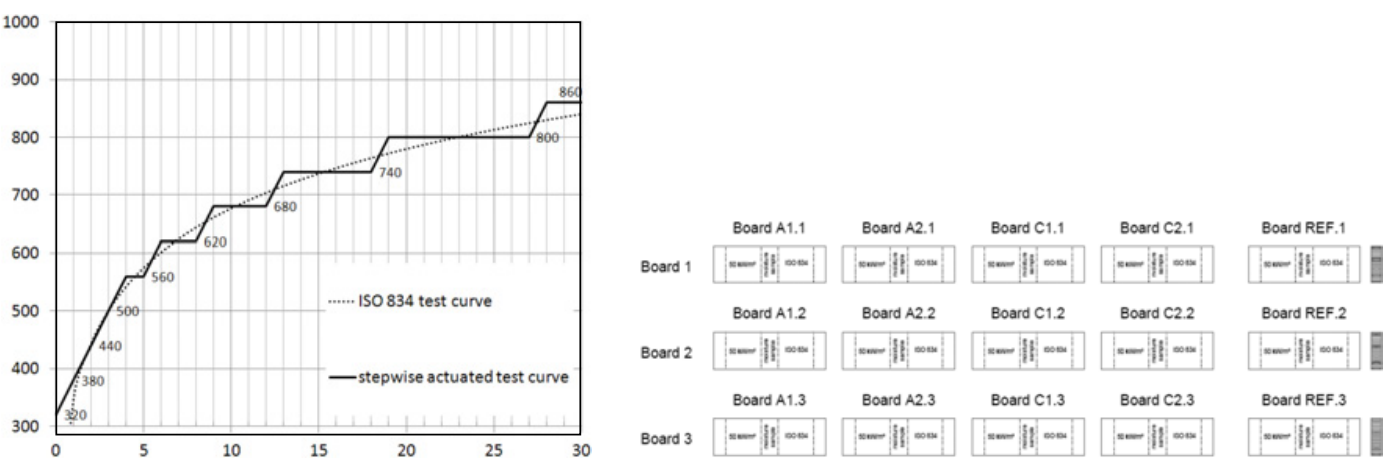

Figure 1. Regulation steps for the standard ISO 834 test curve.

Figure 2. Schematic representation of the sample preparation procedure.

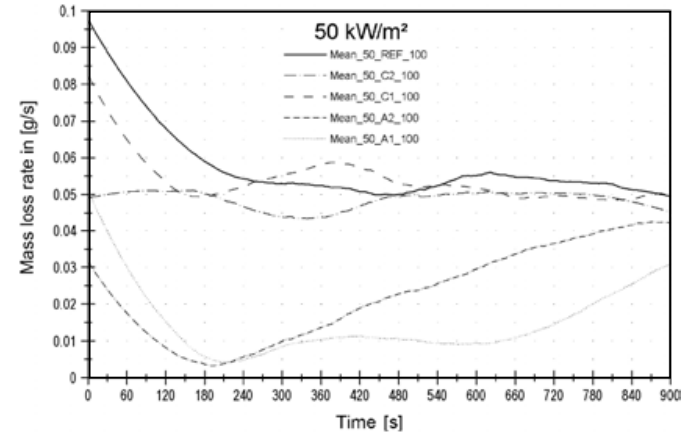

Figure 3. MLR curves with a irradiance of $50 \mathrm{~kW} / \mathrm{m}^{2}$ for different fire retardant products compared to the untreated reference.

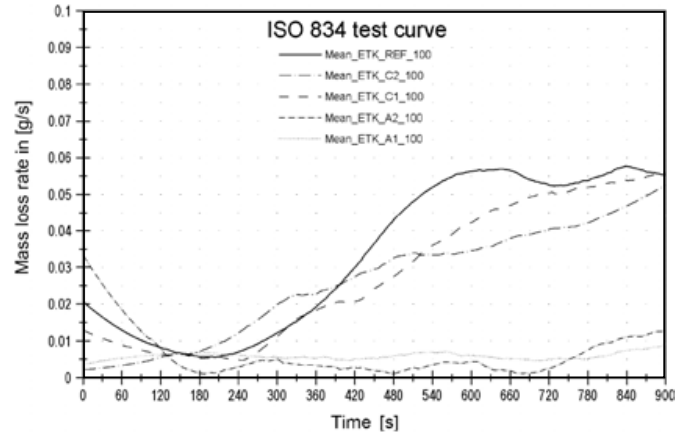

Figure 4. MLR curves with the standard ISO 834 curve for different fire retardant products compared to the untreated reference.

Second the heat release rate (HRR) and the total heat released (THR) is presented and discussed. The THR $_{900}$ is the integral over the HRR from $t=0$ to $t=900 \mathrm{~s}$.

Exposure $50 \mathrm{~kW} / \mathrm{m}^{2}$ : The results of the MLR, illustrated in Fig. 3, exhibit large differences between the fire retardant products. In the first three minutes, the MLR decreases due to water loss from the exposed surface. Only the pressure impregnated series C2 show a nearly continuous MLR for the test duration of 900 seconds. After water loss also the series C2 and REF show a nearly continuous MLR up to the end of test. The two intumescent series A1 und A2 show lower MLR compared to the other series. After water loss the MLR is nearly to zero, before it rises up to the MLR values of the other series.

The total mass loss (TML) gives an overview about the performance of the fire retardant product. Figure 5 show that only the intumescent products reduce the mass loss significantly.

The results of the HRR, illustrated in Fig. 7, exhibits large differences between the fire retardant products. The two intumescent products are effective in reducing the HRR. The pressure impregnated series $\mathrm{C} 2$ also reduces the HRR significant. The series C1 show similar HRR-curve to REF series on a lower level. The steep rise of HRR at test begin can be recognized as ignition of series $\mathrm{C} 1$ and REF.

The total heat release (THR) gives information about the combustion behaviour. Figure 8 show the effectiveness of the intumescent products. Also the pressure impregnated series $\mathrm{C} 2$ reduces energy release significant. 


\section{MATEC Web of Conferences}

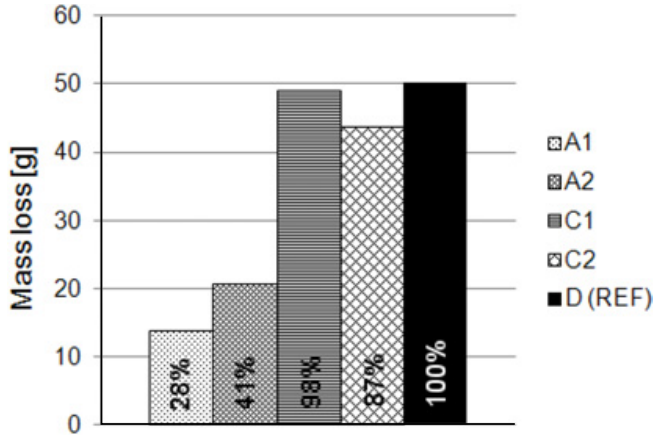

Figure 5. TML 900 with a irradiance of $50 \mathrm{~kW} / \mathrm{m}^{2}$ for different fire retardant products compared to the untreated reference.

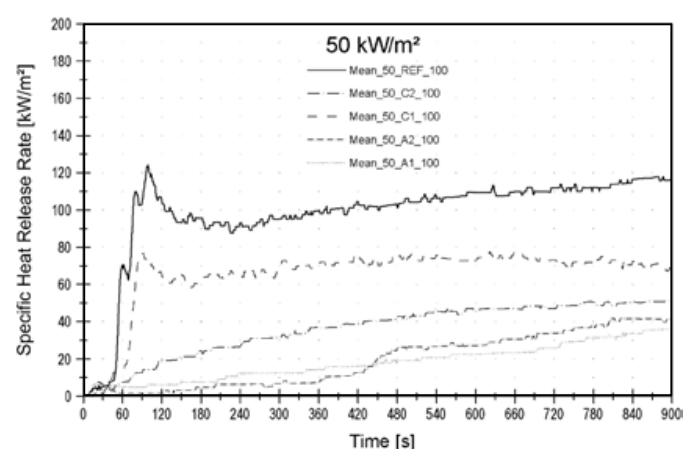

Figure 7. HRR curves with a irradiance of $50 \mathrm{~kW} / \mathrm{m}^{2}$ for different fire retardant products compared to the untreated reference.

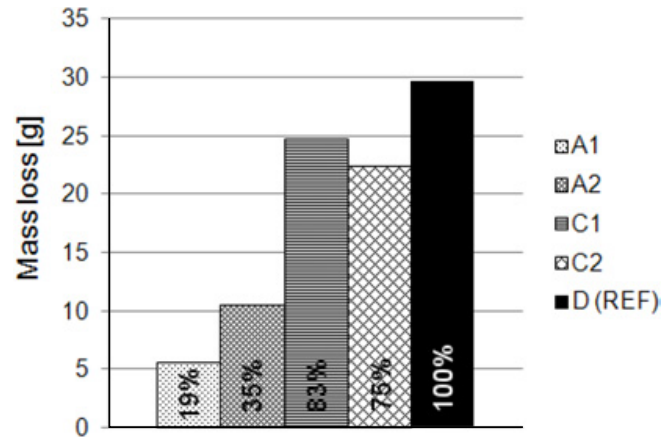

Figure 6. TML 900 with the standard ISO 834 curve for different fire retardant products compared to the untreated reference.

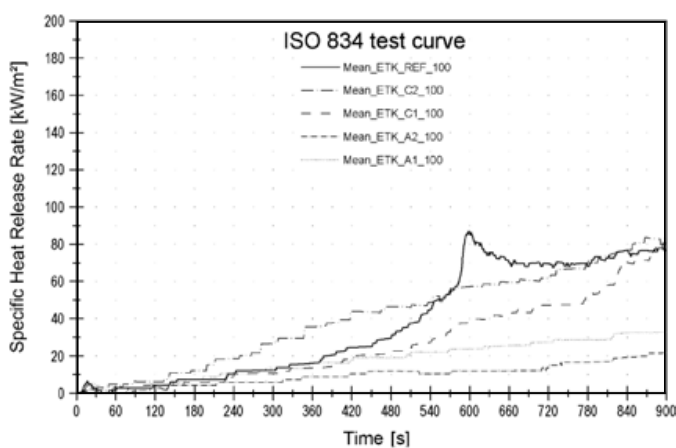

Figure 8. HRR curves with the irradiance of the standard ISO curve for different fire retardant products compared to the untreated reference.

Exposure ISO 834 test curve: If the sample is exposed with the ISO 834 test curve, the differences in MLR between the REF series and the series C1 and C2 are minor (see Fig. 4). The two intumescent series A1 und A2 show significant lower MLR near to zero after water loss.

Figure 6 show that only the intumescent products reduce the mass loss significantly. Also the test series $\mathrm{C} 1$ and $\mathrm{C} 2$ indicate higher fire performance, exposed with the ISO 834 test curve.

If the heat in the sample rises slower, caused by the ISO 834 exposure, also the differences in HRR between the REF series and the series $\mathrm{C} 1$ and $\mathrm{C} 2$ are minor. Series C1 show a higher HRR at the beginning than REF series. The ignition of REF series can be recognized in a short steep rise before results in a peak of HRR. The two intumescent products are effective in reducing the HRR. The lower heat flux at test start gives the intumescent products enough time to expand effective isolating foam.

With lower heat fluxes at test start, the series $\mathrm{C} 1$ and $\mathrm{C} 2$ are in the same range of THR like series REF, see Fig. 10.

\section{SUMMARY}

There are large differences in reaction to fire performance of the tested products. The intumescent coatings on wood reduce significant the MLR and the HRR. The reduction in mass loss (TML) is up to $70 \%$, the reduction in energy release (THR) is about $80 \%$, with a test exposure of $50 \mathrm{~kW} / \mathrm{m}^{2}$. Using the ISO 834 curve as the thermal test exposure the TML reduces up to $80 \%$. The results with test exposure 


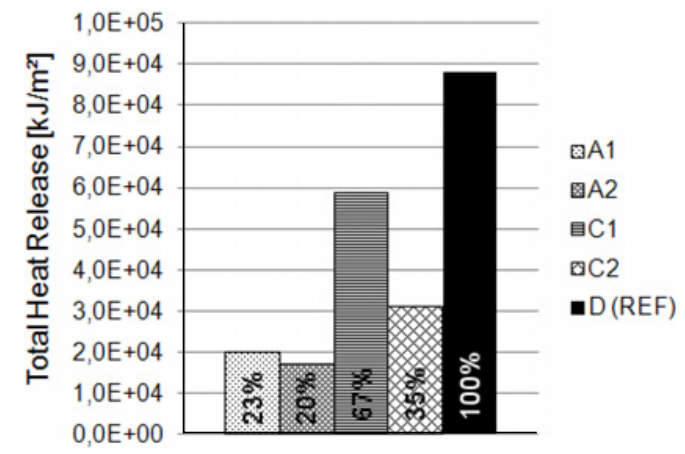

Figure 9. THR T00 $_{9}$ with a irradiance of $50 \mathrm{~kW} / \mathrm{m}^{2}$ for different fire retardant products compared to the untreated reference.

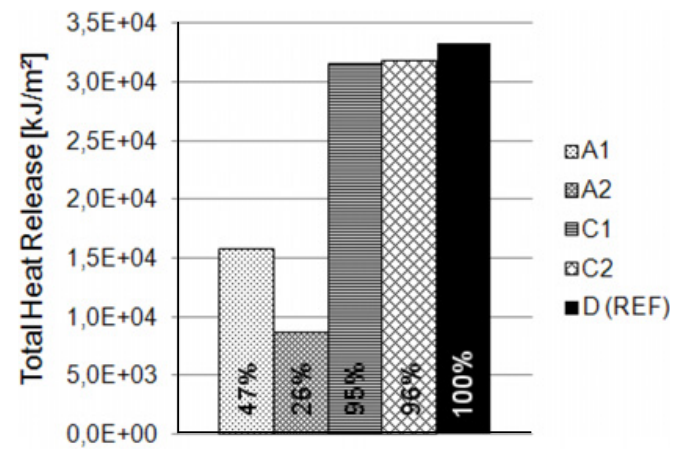

Figure 10. THR 900 curves with the irradiance of the standard ISO curve for different fire retardant products compared to the untreated reference.

of ISO 834 indicate that the THR can be reduced up to $70 \%$ using an intumescent coating under natural fire conditions. The non-intumescent coating and the pressure impregnated treatment show quite similar results within the cone calorimeter test as the untreated reference sample. In this case the question arises if those two products are able to increase fire performance and therefore useful for the protection of structural elements.

The authors gratefully acknowledge the support from the manufacturer those supplied the test materials. They also thank Franz Haas for writing a software program for running and data collection out of the cone calorimeter experiments. This work was partially supported by the "Innovative Wood Protection" project, which is funded by the Tyrolean Government and the European Regional Development Fund (ERDF).

\section{References}

[1] Hartmann, P., Kögl, J., Beikircher, W., "Cone calorimeter tests on treated norway spruce." International Symposium of Structural Fire Engineering, 19-20 April 2013, Prague, Czech Republic

[2] Hakkarainen, T., et al. 2005. "Innovative ecoefficient high fire performance wood products for demanding applications.” State of the art, pp. 2-44. 2005.

[3] EN 13501-1:2002, Fire classification of construction products and building elements - Part 1: Classification using test data from reaction to fire tests. Brussels: European Committee for Standardization

[4] ISO 5660-1. Reaction-to-fire tests - Heat release, smoke production and mass loss rate

[5] ISO 834-1: Fire-resistance tests - Elements of building construction - Part 1. General requirements 